\title{
Maternal Trauma and Adolescent Depression: Is Parenting Style a Moderator?
}

\author{
Leigh A. Leslie, Emily T. Cook \\ Department of Family Science, University of Maryland, College Park, Maryland \\ Email: Ileslie@umd.edu
}

Received 26 March 2015; accepted 28 April 2015; published 6 May 2015

Copyright (C) 2015 by authors and Scientific Research Publishing Inc.

This work is licensed under the Creative Commons Attribution International License (CC BY). http://creativecommons.org/licenses/by/4.0/

c) (i) Open Access

\begin{abstract}
Current research suggests that parents who experience symptoms of trauma transfer distress to their children. The purpose of this study was to understand the possible moderating effect of mothers' parenting style on this relationship for adolescents. This study differs from much of the existing literature in that the adolescents themselves are the reporters of their own well-being. The level of maternal trauma, use of parenting styles, and adolescent depression were examined for a clinical sample of $\mathbf{1 1 3}$ mothers and adolescent dyads. Results indicate that mothers who experience high levels of trauma symptoms are more likely to parent using authoritarian or permissive behaviors. Although mother's level of trauma alone was not related to adolescent's depression, an interaction was found such that mothers experiencing high levels of trauma symptoms who parented with an authoritarian style had adolescents who experienced more depression than those whose mothers were less authoritarian. These findings are discussed in light of the larger literature on "secondary trauma", or the transfer of distress, which often focuses on young children, with mothers as the reporters of both their own and their children's functioning. Clinical implications are also considered.
\end{abstract}

\section{Keywords}

Maternal Trauma, Adolescent Depression, Parenting Style

\section{Introduction}

Children are often negatively affected when mothers exhibit symptoms of trauma (Matsakis, 2004). This transfer of distressing symptoms is referred to as secondary trauma and it can be exacerbated when the relationship with the traumatized person is one of dependence, as is the relationship between a mother and a child (Catherall, 2004). Secondary trauma in children is common when mothers experience a range of traumatic events including 
disasters, emotional abuse, interpersonal or community violence, war, or a host of other threatening or destabilizing situations (e.g., Kiser \& Black, 2005; Van Ee, Kleber, \& Mooren, 2012). Further, the more extensive a mother's trauma history is, the greater the negative outcomes for the child are (Thanker, Coffino, \& Lieberman, 2013), and maternal trauma has a negative added impact on children, even when the children have experienced trauma themselves (Dulmus \& Wodarski, 2000). Negative child outcomes from maternal trauma include problems with attachment, lower school performance, poor social functioning, and a higher incidence of being diagnosed with child disorders such as conduct disorder or attention deficit hyperactivity disorder (Rossman, 1999).

Many factors may moderate or protect against the impact of maternal trauma, including the mental health of the other parent, the stability of the spousal relationship, and the support of the family's community (Garbarino, Bradshaw, \& Kostelny, 2005). One possible moderator that has received considerable attention is parenting, or the characteristics of interactions between a mother and a child. The majority of empirical evidence suggests that trauma-related stress negatively impacts the mother-child relationship and may undermine effective parenting (Lombardo \& Motta, 2008). Kiser \& Black (2005) conducted a meta-analysis of the clinical and research literatures addressing the connections between chronic traumatic exposure and family processes, specifically focusing on low-income urban families, and found that mothers exposed to high levels of trauma more consistently engaged in parenting characterized by insensitivity, reactivity, harshness, and lack of responsiveness. More recently, Van Ee \& colleagues (2012) found that for mothers experiencing war-related trauma, higher levels of post-traumatic stress symptoms were related to less emotional availability to their infants and young children.

While several studies have documented the impact of maternal trauma on certain parenting behavior, and subsequently, child's well-being, few studies have examined the moderating effects of parenting style, per se. Parenting style refers to a systematic pattern of parenting practices that encompass a parent's overall approach to responsiveness and control (Maccoby \& Martin, 1983). In her seminal work on parents' interaction with their preschoolers, Diana Baumrind (1971) revealed three prototypical parenting styles: authoritative, authoritarian, and permissive. Authoritative parenting involves high levels of parental acceptance and involvement, adaptive control techniques, and granting age-appropriate autonomy to children. In contrast, authoritarian parenting is characterized by low acceptance and involvement, coercive control, and low autonomy granting, while permissive parenting is characterized by inappropriately high levels of indulgence and involvement, low control, and developmentally inappropriate autonomy granting. Baumrind's findings and those of others who extended her work consistently find that authoritative parenting is the most effective parenting strategy and is associated with a wide range of positive outcomes for children (Berk, 2005). Further, an authoritative parenting style has also been linked to high levels of child resilience, or protecting the child from negative impacts of family stress or hardship (Pettit, Bates, \& Dodge, 1997). Therefore, it is possible that children may be protected from the negative impact of maternal trauma when mothers are able to engage in authoritative parenting.

However, a review of the literature on the intergenerational effects of trauma (Kaitz et al., 2009) illuminates how difficult it may be for mothers who have experienced high levels of trauma to engage in authoritative parenting. While not examining the three parenting styles by name, Kaitz and her colleagues describe compilations of parenting practices analogous to Baumrind's parenting styles. The authors summarize studies indicating that mothers who are affectively disturbed by trauma or who are highly symptomatic of posttraumatic stress are unable to provide sensitive guidance, regulation, or fun during encounters with their children. They explain these parenting challenges with evidence from literature concerning maternal depression and anxiety. In particular, mothers' interactions with their children are disrupted by the traumatic experience such that depressed mothers are unable to accurately appraise and respond to their children's needs. This disconnect may result in the mother being unaware of her child's needs and not making appropriate demands or providing appropriate control for the child. This withdrawn stance, typical of the permissive parenting style, may be useful for mothers, as it can protect traumatized mothers from further distressing emotional arousal. Kaitz and colleagues also conclude that some mothers respond to trauma by exaggerating their responsiveness to children, resulting in an overly controlling manner of interaction. These parenting behaviors align with the authoritarian style.

In order to further our understanding of factors that may protect children from the deleterious effects of maternal trauma, the current study will examine the moderating effects of parenting style. Additionally, while the bulk of the research on maternal trauma and parent-child interaction has looked at school age children with mothers being the reporters of child outcomes (e.g., Wyman et al., 1999), we will focus on the potential moderating effects of parenting style on adolescent children, with the adolescents themselves as reporters of their well-being. Thus, the present study addresses three questions. First, do adolescents report higher levels of depression when 
their mothers report the experience of trauma symptoms? Second, are mothers who report symptoms of trauma more likely to engage in a particular parenting style? And third, do mothers' styles of parenting serve as a moderator between maternal trauma symptoms and their adolescents' experience of depression?

\section{Methods}

\subsection{Sample}

The data for this study were collected from 113 families seeking mental health therapy at a university based family therapy clinic in the eastern US. Families were selected for participation in the present study based on several requirements. First, the therapy treatment unit was a family which included one mother and at least one child between the ages of 12 and 18. If more than one child in the appropriate age group was present for therapy, selection of the child participant alternated between the oldest and youngest child present.

Mothers' $(n=113)$ mean age was 41 , with ages ranging from 29 to 54 years old. Sixty-two mothers selfidentified as African American (54.9\%), 25 as White (22.1\%), 12 as Hispanic (10.6\%), 2 as Asian/Pacific Islander $(1.8 \%)$, and 12 as other/multiracial $(10.6 \%)$. Thirty-one mothers were married and living with their partners $(27.4 \%)$, 15 were cohabiting (13.3\%), 44 were separated, divorced, or widowed (38.9\%), and 20 were single (17.7\%). Three mothers did not report their relationship status. Mothers had between 1 and 6 children living at home with them, with an average of 2.3 children. Thirty mothers reported having at least one child not living in their home. Many mothers held college degrees $(n=38)$ or had attended college $(n=39)$. Their incomes ranged from $\$ 0$ to $\$ 160,000$, with a mean of $\$ 34,244$.

Of the 113 children, 65 were female $(57.5 \%)$ and 48 were male $(42.5 \%)$, with ages ranging from 12 to $18,(M$ $=14.7)$. Sixty-six children self-identified as African American (58.4\%), 20 as White (17.7\%), 8 as Hispanic (7.1\%), 1 as Asian/Pacific Islander (9\%), and 18 as other/multiracial (15.9\%).

\subsection{Procedure}

Each family in the study initiated therapy services by first calling the clinic and completing an intake interview over the telephone. The intake worker gathered information such as the presenting problem, demographic information, and family structure. The assigned therapist contacted the family by telephone and explained that the first session would involve paperwork assessments and that this initial session would be free of charge.

During the first session, all present family members 12 years of age and older signed an informed consent agreement and completed the entire questionnaire battery, which assessed variables such as depression, trauma symptoms, relationship styles, issues of family conflict, family and social support, drug and alcohol use, relationship distress, and parenting practices. Of these, the Trauma Symptom Inventory, Parenting Practices Questionnaire, and Beck Depression Inventory were used for the purposes of this study.

\section{Measures}

Trauma Symptom Inventory. Mothers' experience of trauma was assessed using the Trauma Symptom Inventory (TSI; Briere, 1995). The TSI was created for use in clinical settings to assess the experience and severity of trauma-related symptoms. The original 100 item TSI has 13 subscales, three validity scales, and ten clinical scales. However, due to the extensive battery of assessments required of new clients, the clinic administers a shortened version of the TSI, which includes 42 items and five clinical scales; intrusive experiences, defensive avoidance, dissociation, anger/irritability, and anxious arousal. These five scales correspond to the five DSM-IV diagnostic criteria for PTSD. The TSI outcome data have been normed to the general population (men and women, 18 years and older), and university, clinical, and U.S. Navy recruit samples. Race accounted for only $2 \%$ to $3 \%$ of the variance on the TSI scales; therefore, Briere (1995) recommends that the TSI clinical scales not be adjusted for race.

Respondents are instructed to answer each question based on how often in the past six months each symptom was experienced, ranging from 0 "Never" to 3 "Often". The raw scores for each subscale are totaled, converted to $\mathrm{T}$ scores, and then compared to normative $\mathrm{T}$ scores. Higher total raw and $\mathrm{T}$ scores generally indicate greater degrees of symptomology, with a total T score above 65 considered clinically significant (Briere, 1995). The five clinical subscales used on the clinic's abbreviated version are internally consistent (mean alpha coefficients range from .84 to .87) and have sufficient convergent and predictive validity (predicting PTSD status in over $90 \%$ 
of the cases). Also, the TSI has high incremental validity, meaning its scores predicted the "victimization variance" beyond what was accounted for by other trauma symptom measures (Briere, 1995: p. 43).

Parenting Practices Questionnaire. In order to measure the mother's parenting style, the Parenting Practices Questionnaire (PPQ; Coolahan, 1997) was used. There are 62 items on the PPQ, which cluster on three parenting styles: authoritarian, authoritative, and permissive. The authoritative parenting scale consists of 27 items that measure dimensions of warmth, reasoning/induction, good natured/easy going, and democratic. The authoritarian parenting scale consists of 20 items along four dimensions of verbal hostility, corporal punishment, nonreasoning/punitive, and directiveness. Finally, the permissive parenting scale consists of 15 items that emphasize lack of follow through, ignoring misbehavior, and lack of parenting self-confidence.

The PPQ instructs the participant to select the response that best indicates how often certain parenting behaviors are performed. The participant answers on a Likert-type scale that ranges from 1 "Never", to 3 "About half the time", to 5 "Always". Respondents receive scores on each of the three parenting scales. The three parenting style scales are internally consistent, with Cronbach alphas of $.87, .74$, and .77 for the authoritative, authoritarian, and permissive parenting scales respectively. The PPQ has also been shown to have good construct validity, with $93 \%$ of items loading on only one of the three dimensions (Coolahan, 1997).

Beck Depression Inventory. In order to measure a child's report of depression, the Beck Depression Inventory (BDI; Beck, Rush, Shaw, \& Emery, 1979) was used. The BDI consists of 21 items that describe the symptoms and attitudes typically expressed by depressed individuals. It is proven as a reliable measure, with good internal consistency (mean coefficient alpha $=.86$ ) and stability (correlation coefficients between .48 and .86 ). The BDI also has excellent content, concurrent, discriminate, construct, and factorial validity. Scores on the BDI are related to suicidal ideation, alcoholism, and adjustment disorders, and they discriminate from anxiety disorders (Beck, Steer, \& Garbin, 1988).

The BDI begins with instructions for the participant to rate his or her feelings in the past week. Each response is reported on a Likert-type scale that ranges from 0 to 3, where higher scores indicate more severe depression symptoms. Responses to the 21 items are summed for a total BDI score. The total score indicates level of depression: scores less than 10 indicate none to minimal depression, scores 10 - 18 indicate mild to moderate depression, score 19 - 29 indicate moderate to severe depression, and scores 30 - 63 indicate severe depression. Scores above 15 are considered clinically significant (Beck, 1996). Although the BDI was developed for use on adult populations, it is accurate in detecting depression among adolescents ages 13 to 18 (Sitarenios \& Kovacs, 1999).

\section{Results}

The present study was designed to examine the relation between maternal trauma symptoms and adolescent depression, as well as examine the moderating effect of parenting styles.

For the first question regarding the relation between mother's level of trauma symptoms and her child's level of psychological distress, a Pearson correlation was conducted. Contrary to expectations, the results indicated no significant relationship between mother's level of trauma and child's level of depression, $r(113)=.08, p$ $=.38$.

For the second study question, three Pearson correlations were conducted to test the relations between mother's level of trauma symptoms and her use of each parenting style. Results differed by parenting style. Mother's level of trauma symptoms and her level of authoritative parenting behaviors were not significantly correlated, $r(113)=-.07, p=.50$. However, mother's level of trauma symptoms and her level of authoritarian, $r(113)=.25$, $p<.01$, and permissive, $r(113)=.45, p<.01$, parenting behaviors were significantly positively correlated. Mothers who experience higher levels of trauma symptoms were more likely to use authoritarian and permissive parenting behaviors than mothers who experience lower levels of trauma symptoms.

Three step-wise multiple regressions, one for each parenting style, were conducted to test the third study question investigating the moderating effect of parenting style. For each regression, an interaction variable was created by multiplying mother's level of trauma symptoms with her respective level of parenting behaviors on authoritative parenting, authoritarian parenting, and permissive parenting scores. The level of child depression was the dependent variable. Maternal level of trauma was entered first, the parenting style was entered second, and each interaction variable was entered third. As can be seen in Table 1 and Table 2, there was no moderating effect for authoritative or permissive parenting. However, a significant moderating effect was found for authoritarian parenting, as shown in Table 3 . 
In order to understand the direction of the moderating effects for authoritarian parenting, children's depression means were examined under conditions of high and low maternal trauma and authoritarian parenting. For these analyses, the level of maternal trauma symptoms was divided in two categories based on a median split between "low scores" (a score of 0 - 39) and "high scores" (a score of 40 - 121). The level of authoritarian parenting were also divided in two categories based on a median split between "low scores" (25 - 43) and "high scores" (44 - 82). As can be seen in Table 4, under conditions of low maternal trauma, mother's use of authoritarian parenting strategies does not appear to affect child depression. The effect does seem to be evident, however, under conditions of high trauma. Mothers experiencing high levels of trauma symptoms who parent with a high use of authoritarian behaviors have children who experience more depression than those whose mothers who use low levels of authoritarian behaviors.

Table 1. Mother trauma (TSI) and authoritative parenting.

\begin{tabular}{ccccc}
\hline & Standardized Coefficient & & \\
\hline Variable & Beta & $\mathrm{t}$ & Sig. \\
\hline Trauma & -.39 & -.51 & .61 \\
Authoritative Parenting & -.14 & -.70 & .49 \\
Trauma $\times$ Authoritative Parenting & .49 & .62 & .53 \\
\hline
\end{tabular}

Table 2. Mother trauma (TSI) and permissive parenting.

\begin{tabular}{cccc}
\hline & \multicolumn{3}{c}{ Standardized Coefficient } \\
\hline Variable & Beta & $\mathrm{t}$ & Sig. \\
\hline Trauma & .43 & 1.29 & .20 \\
Permissive Parenting & -.05 & -.29 & .78 \\
Trauma $\times$ Permissive & -.35 & -.83 & .40 \\
\hline
\end{tabular}

Table 3. Mother trauma (TSI) and authoritarian parenting.

\begin{tabular}{cccc}
\hline & Standardized Coefficient & & \\
\hline Variable & Beta & $\mathrm{t}$ & Sig. \\
\hline Trauma & -.64 & -1.72 & .09 \\
Authoritarian Parenting & -.14 & -.81 & .42 \\
Trauma $\times$ Authoritarian & .82 & 1.91 & $.05^{*}$ \\
\hline${ }^{*} p=.05$. & & & \\
\end{tabular}

Table 4. Children's depression (BDI) scores for low and high maternal trauma and authoritarian parenting.

\begin{tabular}{rcc} 
& Low Authoritarian & High Authoritarian \\
\hline Low Maternal Trauma & 10.90 & 10.18 \\
High Maternal Trauma & 9.34 & 13.30 \\
\hline
\end{tabular}

\section{Discussion}

The purpose of this study was to investigate the impact of symptoms resulting from maternal experience of trauma on parenting styles and adolescent depression. Previous research shows a transfer of distress from traumatized mothers to their children, and a deleterious effect of trauma on mother's parenting (Dulmus \& Wodarski, 2000; Kaitz et al., 2009). 
The current study both aligns with and differs from previous research on the complex relationships between maternal trauma, parenting behaviors, and child psychological distress. One of the most interesting differences in the findings of this study is that it did not replicate findings of secondary trauma in children of mothers who experience high levels of trauma symptoms. A possible explanation for this finding is the use of adolescent participants. Much of the literature that documents secondary trauma in children uses samples of children younger than age 12. It is possible that adolescents are better protected from their parent's trauma symptoms than younger children, due to their more developed coping skills and support systems, such as peers or other significant adults such as a teachers or coaches. Younger children are more likely than adolescents to be dependent on and to spend time with their mothers. Thus, they may be more vulnerable to the transfer of distress. Additionally, adolescents are at a more advanced level of cognitive processing and may be able to better reason and understand their parent's trauma in a way that protects them from a transfer of distress. It is also possible that adolescents who are negatively impacted by their parent's trauma symptoms respond in other ways not assessed in the current study. For example, adolescents may respond with anger or anti-social behaviors such as substance abuse, rather than with symptoms of depression or anxiety. It is also worth noting that the lack of transfer was found in a sample in which the adolescents themselves reported on their level of depression. The link between maternal trauma and negative outcomes for children is often found in studies in which the mother is the reporter of both her own trauma and her child's well-being.

Similar to previous research, the current study supported the link between the experience of trauma and less than optimal parenting. Mothers in the current study were more likely to use authoritarian or permissive parenting behaviors when they also experienced high levels of trauma symptoms. Furthermore, mothers' use of authoritarian and use of permissive parenting behaviors were highly correlated. In a secondary analysis, authoritarian behaviors and permissive behaviors were significantly positively related, $r(111)=.35, p<.01$, such that mothers who reported high levels of authoritarian behaviors were also likely to report high levels of permissive behaviors. Previous research supports the relation that stressed mothers are more likely than non-stressed mothers to be generally lenient in their behavioral standards for their children and yet also engage in harsh tactics for control (Cummings et al., 2000; Kaitz et al., 2009). The combination of internalizing trauma symptoms, such as depression and emotional numbing, and externalizing trauma symptoms, such as hyper-arousal and aggression, may lead mothers to tend towards the withdrawn behaviors of permissive parenting and the hyper-vigilant behaviors of authoritarian parenting.

While maternal trauma per se did not seem to impact adolescents' level of depression in the current study, how mothers parent through their traumatic symptoms did appear to have an impact. Based on previous research, it is not surprising that mothers with trauma symptoms tend to use both authoritarian and permissive parenting behaviors, however, it was only the use of an authoritarian parenting style by these mothers that was related to adolescent depression. Mothers who experienced higher levels of trauma symptoms and who used higher levels of authoritarian parenting had adolescents who experienced higher levels of depression. Authoritarian parenting is characterized by high levels of criticism and coercive control and by low levels of warmth and acceptance (Baumrind, 1971). Some authors suggest that the authoritarian behaviors of traumatized parents stem from their tendency to go to exaggerated lengths to protect their children from the kinds of traumatic experiences they themselves encountered (Kaitz et al., 2009). In general, this type of authoritarian behavioral control may lead to infantilizing children and restricting their development of autonomy and confident decision making. This may explain, in part, why it was this parenting style specifically that was most problematic for adolescents. At the time of life when developmentally a child may be attempting to separate from parents and develop more independence, the restrictive nature of authoritarian parenting could be most distressing for the adolescent. It is important to remember, however, that an authoritarian parenting style alone was not related to adolescent depression. This parenting style had to occur in the presence of high maternal trauma for the effect to be seen. It may be that having a restrictive mother who does not demonstrate warmth and who, herself, seems distressed can have a debilitating effect on an adolescent.

When reviewing the findings of this study, limitations should be considered. First, it is possible that the use of a convenience clinical sample affected the means of the sample. Although the clinic serves an ethnically and socioeconomically diverse population, the sample may not be representative of the larger population, in that these were families who were both experiencing some family problems and were seeking help for the problem. Additionally, interpretations of the findings need to be made in the correlational context of the study design. Given that causal connections cannot be established, it must be acknowledged that the adolescents' depression could 
have preceded the mothers' use of authoritarian parenting style or her trauma.

In spite of these limitations, the current study both adds to the body of knowledge on secondary trauma and suggests important avenues to consider as this work moves forward. First, while previous research has established that secondary trauma in children is likely when mothers experience trauma, these findings suggest that this relationship may be different for adolescents. Due to their potentially more developed cognitive processing and coping skills, as well as their increased amount of time spent away from their mothers, it is possible that the impact of maternal trauma is less direct for adolescents than it is for younger children. Future studies should seek to more clearly understand the potential and mechanisms for secondary trauma in adolescents. Second, using mothers as reporters of their own trauma and parenting style and adolescents as reporters of their own depression, this study was able to establish a connection between a particular parenting style and adolescent depression under conditions of high maternal trauma. However, given that the direct effect of maternal trauma was not found as it has been in previous work where mothers were the reporters of child outcomes, it raises the question of who is the optimal reporter of child well-being. It is certainly possible that the disengaged or hypervigilent symptoms of trauma may hinder mothers' ability to accurately assess their children's emotional and behavioral states. While younger children may not be capable of providing such information, the findings of this study suggest that future work on secondary trauma should consider including the input of additional reporters, such as teachers or other non-traumatized parents or care-givers, when examining child outcomes.

Finally, the results of the present study have implications for clinical practice. Maternal experience of trauma is nuanced, as is its impact on parenting behaviors and child well-being, and may be best assessed with a comprehensive assessment format (Briere \& Scott, 2006). Given that authoritarian parenting behaviors were related to higher depression among adolescents under conditions of high maternal trauma, clinicians using psychoeducation could coach mothers to parent through their trauma symptoms in other ways to reduce the transfer of distress. Clinicians using a comprehensive, systems-oriented framework may facilitate a more meaningful dialogue with their clients about their traumatic experiences and how those experiences impact different aspects of their life, including parenting behaviors.

\section{Conclusion}

The findings from this study do support the ongoing concern that when parents experience trauma, children may suffer too. Identifying the mechanisms through which children are affected and how they may differ based on characteristics of both the child and the parent are important as we strive to develop strategies and interventions to assist children who may experience secondary trauma.

\section{References}

Baumrind, D. (1971). Current Patterns of Parental Authority. Developmental Psychology Monograph, 4, 1-103. http://dx.doi.org/10.1037/h0030372

Beck, A. T., Rush, A. J., Shaw, B. F., \& Emery, G. (1979). Cognitive Therapy of Depression. New York: Guilford Press.

Beck, A. T., Steer, R. A., \& Garbin, M. G. (1988). Psychometric Properties of the Beck Depression Inventory: Twenty-Five Years of Evaluation. Clinical Psychology Review, 8, 77-100. http://dx.doi.org/10.1016/0272-7358(88)90050-5

Berk, L. E. (2005). Infants, Children, and Adolescents (5th ed.). Boston, Massachusetts: Pearson.

Briere, J. (1995). Trauma Symptom Inventory (TSI): Professional Manual. Odessa, Florida: Psychological Assessment Resources, Inc.

Briere, J., \& Scott, C. (2006). Principles of Trauma Therapy: A Guide to Symptoms, Evaluation, and Treatment. New York: Sage Publications.

Catherall, D. R. (2004). Handbook of Stress, Trauma, and the Family. New York: Brunner-Routledge.

Coolahan, K. C. (1997). Empirical Relationships among Parenting Styles, Determinants of Parenting, and Children's School Readiness in Urban Head Start Families. Unpublished Doctoral Dissertation, Pennsylvania: University of Pennsylvania.

Cummings, E. M., DeArth-Pendley, G., Schudlick, T. D., \& Smith, D. A. (2000). Parental Depression and Family Functioning: Toward a Process-Oriented Model of Children's Adjustment. In S. R. H. Beach (Ed.), Marital and Family Processes in Depression: A Scientific Foundation for Clinical Practice (pp. 89-110). Washington, DC: American Psychological Association.

Dulmus, C. N., \& Wodarski, J. S. (2000). Trauma-Related Symptomatology among Children of Parents Victimized by Urban Community Violence. American Journal of Orthopsychiatry, 70, 272-277. http://dx.doi.org/10.1037/h0087794 
Garbarino, J., Bradshaw, C. P., \& Kostelny, K. (2005). Neighborhood and Community Influences on Parenting. In T. Luster, \& L. Okagaki (Eds.), Parenting: An Ecological Perspective (2nd ed., pp. 297-318). Mahwah, NJ: Lawrence Erlbaum Associates, Publishers.

Kaitz, M., Levy, M., Ebstein, R., Faraone, S. V., \& Mankuta, D. (2009). The Intergenerational Effects of Trauma from Terror: A Real Possibility. Infant Mental Health Journal, 30, 158-179. http://dx.doi.org/10.1002/imhj.20209

Kiser, L. J., \& Black, M. M. (2005). Family Processes in the Midst of Urban Poverty: What Does the Trauma Literature Tell Us? Aggression and Violent Behavior, 10, 715-750. http://dx.doi.org/10.1016/j.avb.2005.02.003

Lombardo, K. L., \& Motta, R. W. (2008). Secondary Trauma in Children of Parents with Mental Illness. Traumatology, 14, 57-67. http://dx.doi.org/10.1177/1534765608320331

Maccoby, E. E., \& Martin, J. A. (1983). Socialization in the Context of the Family: Parent-Child Interaction. In P. H. Mussen, \& E. M. Hetherington (Eds.), Handbook of Child Psychology: Vol. 4. Socialization, Personality, and Social Development (pp. 1-101). New York: Wiley.

Matsakis, A. (2004). Trauma and Its Impact on Families. In D. R. Catherall (Ed.), Handbook of Stress, Trauma, and the Family (pp. 15-31). New York: Brunner-Routledge.

Pettit, G. S., Bates, J. E., \& Dodge, K. A. (1997). Supportive Parenting, Ecological Context, and Children's Adjustment: A Seven-Year Longitudinal Study. Child Development, 68, 908-923. http://dx.doi.org/10.2307/1132041

Rossman, B. B. R. (1999). Multiple Risks for Children Exposed to Parental Violence: Family Factors, Psychological Maltreatment, and Trauma. Journal of Aggression, Maltreatment \& Trauma, 2, 207-237. http://dx.doi.org/10.1300/J146v02n02 10

Sitarenios, G., \& Kovacs, M. (1999). Use of the Children's Depression Inventory. In M. Maruish (Ed.), The Use of Psychological Testing for Treatment Planning and Outcomes Assessment (2nd ed., pp. 267-298). Mahwah, NJ: Lawrence Erlbaum Associates, Publishers.

Thanker, D., Coffino, B., \& Lieberman, A. (2013). Maternal Symptomatology and Parent-Child Relationship Functioning in a Diverse Sample of Young Children Exposed to Trauma. Journal of Traumatic Stress, 26, 217-224.

Van Ee, E., Kleber, R. J., \& Mooren, T. T. (2012). War Trauma Lingers On: Associations between Maternal Post-Traumatic Stress Disorder, Parent-Child Interaction, and Child Development. Infant Mental Health Journal, 33, 459-468. http://dx.doi.org/10.1002/imhj.21324

Wyman, E. L., Cowen, W. C., Work, W. C., Hoyt-Meyers, L., Magnus, K. B., \& Fagen, D. B. (1999). Caregiving and Developmental Factors Differentiating Young At-Risk Urban Children Showing Resilient versus Stress-Affected Outcomes: A Replication and Extensions. Child Development, 70, 645-659. http://dx.doi.org/10.1111/1467-8624.00047 